\title{
Prevalence and maternal socio-demographic factors associated with stillbirth in health facilities in Anambra, South-East Nigeria
}

\author{
Nonye E Anyichie, Evelyn N Nwagu
}

Department of Human Kinetics and Health Education, University of Nigeria, Nsukka, Enugu state, Nigeria.

Emails: nonyelumanyichie@gmail.com,evelyn.nwagu@unn.edu.ng

\begin{abstract}
Background: Stillbirth is a major adverse perinatal outcome especially in low and middle income countries across the globe. Certain factors relating to mothers from such countries may be associated with this adverse condition.

Objectives: To determine the prevalence of stillbirth and also explore the maternal socio-demographic factors associated with stillbirth among mothers in rural communities in Anambra Central Senatorial District of Anambra State Nigeria who gave birth between January 2012 and December 2016.

Methods: All case files of mothers who were delivered of their babies were accessed at the sampled health facilities in the district. Data were collected using a structured proforma. A total of 313 stillbirth cases were recorded across the health facilities from 2012-2016.

Results: The highest prevalence of stillbirth was recorded in 2012 (38.07 per 1,000 total births). The prevalence of stillbirth was significantly associated with the maternal level of education, occupation, age and type of health facility the mother utilized $(\mathrm{p}<0.05)$.

Conclusions: We recommend that women empowerment should be a priority at both family and community levels to enable women to seek and obtain necessary care during pregnancy and delivery.

Keywords: Stillbirth; mothers; prevalence; health facilities.

DOI: https://dx.doi.org/10.4314/ahs.v19i4.27

Cite as: Anyichie NE, Nwagu EN. Prevalence and maternal socio-demographic factors associated with stillbirth in bealth facilities in Anambra, South-East Nigeria. Afri Health Sci.2019;19(4):3055-3062.bttps:/ / dx.doi.org/10.4314/abs.v19i4.27
\end{abstract}

\section{Introduction}

Stillbirth is one of the major adverse perinatal outcome across the globe. ${ }^{1}$ A research study showed that in 2015 alone, there were 2.6 million third trimester stillbirths, out of which 98 per cent occurred in low and middle-income countries, and over three-quarters of these, occurred in sub-Saharan Africa and South Asia. ${ }^{2}$ The above study showed that only ten countries carry the burden of over 65 per cent of the total stillbirths in the world and Nigeria was ranked second among them with an estimated 313,700 stillbirths (42.9 per 1,000 total births).

\section{Corresponding author:}

Evelyn N Nwagu,

Department of Human Kinetics and Health

Education,

University of Nigeria, Nsukka, Enugu state, Nigeria.

Phone: +2348139707903

Email: evelyn.nwagu@unn.edu.ng
The prevalence of stillbirth however, varies between localities even in a particular country. In Nigeria, the prevalence of stillbirth varied from as low as 39 per 1000 deliveries in South-South Nigeria, to as high as 48 per 1000 deliveries in Northern Nigeria, and 23 per 1000 deliveries in South-East Nigeria. ${ }^{3}$ This variation may be attributed to differences in the availability of health facilities as well as cultural differences among different ethnic groups.

In many Nigerian cultures, pregnancy is often a fulfilling experience, and the birth of a live baby is a cause for rejoicing. ${ }^{4}$ It is the expectation of every pregnant woman to give birth safely, hear the cry of the baby, as well as carry the baby in her arms. Similarly, the family and the community members expect to see the woman go through the pregnancy period without complications, and give birth to a live healthy baby. This expectation is not realized in many situations as a result of stillbirth. ${ }^{5}$

Despite the scourge of stillbirth in many low and middle-income countries, global efforts for improved preg-

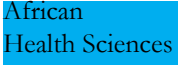

3055

(C) 2019 Anyichie et al. Licensee African Health Sciences. This is an Open Access article distributed under the terms of the Creative commons Attribution License (https://creativecommons.org/licenses/BY/4.0), which permits unrestricted use, distribution, and reproduction in any medium, provided the original work is properly cited. 
nancy outcome and reduction of stillbirth appear to be missing from most health agenda. Millions of stillbirths still occur each year. ${ }^{6,7}$ At the family level, a stillbirth is associated with grief and negative emotions, and at the country level, high stillbirth rates add to the perinatal mortality rates for the country. ${ }^{8}$ These notwithstanding, in eastern parts of Nigeria for instance, stillbirths are often blamed on the woman or on evil spirits (ogbanje myth). Such apportioning of blame does not allow sustained effort at promoting maternal health ${ }^{10}$ so as to prevent stillbirth and other negative outcomes of pregnancy. Families experience stillbirth, yet these deaths remain under-reported, and the solutions understudied. ${ }^{11}$ Although data on the prevalence of stillbirth exist from some tertiary health facilities in Nigeria, ${ }^{12,13}$ there is still a need to identify the prevalence and demographic factors of stillbirth in primary and secondary health facilities among rural Igbo dwellers since the factors associated with stillbirth among this ethnic group may differ from the factors associated with stillbirth in other parts of Nigeria.

Nigerian has over 400 ethnic groups with diverse cultural beliefs and practices. ${ }^{14}$ One of the major ethnic groups in Nigeria is Igbo. Anambra is a state in Southeastern Nigeria whose indigenes are Igbos. The inhabitants of Anambra are largely farmers and artisans. Many of them are also entrepreneurs who engage in buying and selling. These activities occupy most of their time such that many of the mothers may be too busy to seek health care during pregnancy, which predisposes them to stillbirth. The purpose of this study was therefore to identify the prevalence of stillbirth and the maternal socio-demographic factors associated with stillbirth among mothers who use primary and secondary health facilities in Anambra, South-East Nigeria. Identification of such factors will help in developing appropriate intervention strategies to curb stillbirth in the area of study.

\section{Methods}

We conducted a retrospective study of the prevalence and socio-demographic factors associated with stillbirth among women of childbearing age (15-49 years) who used primary and secondary health facilities in Anambra state from 2012-2016. The population for the study comprised of all mothers who gave birth in primary and secondary health facilities in Anambra state, Nigeria from 2012 to 2016. Out of the three senatorial districts that make up the state, Anambra Central Senatorial District was randomly selected for the study. Using simple random sampling technique, 35 health facilities (comprising twenty-nine primary health facilities and six secondary health facilities) were selected from the 60 health facilities in Anambra Central Senatorial District using proportionate random sampling technique. Ethical clearance was obtained from the ethical board of the Anambra State Ministry of Health (Ref NO: MH/AWK/M:321/129). Access to files was granted by the management of health facilities. All case files that met the criterion for inclusion were eligible for the study. Two visits were made to each of the selected health facilities. The first visit was for the researchers to introduce themselves to the management of the health facility and also to get acquainted with the health facility, while the second visit was for the purpose of extracting data from clients' folders. Records of stillbirth (fetuses 28 weeks and above) from January, 2012 to December, 2016 were extracted from the maternity wards and record units of the sampled health facilities. Data were verified and reviewed for improbable, implasible and missing values. Prevalence of stillbirth was examined by demographic variables of age, occupation, level of education, parity and type of health facility. Frequencies and percentages of the reported stillbirths were collated and computed on yearly basis. Prevalence rate was calculated. Chi square test of association was computed using $\mathrm{R}$ Stats chi-square calculator in Excel worksheet 15 to test for significant differences in the number of stillbirths among various categories of mothers. Null hypotheses were tested at 0.05 level of significance.

\section{Results}

In all sampled health facilities, 313 cases of stillbirth were recorded from 2012 to 2016. Across the years, highest cases of stillbirth were recorded in 2012 (74 cases of stillbirth; 38.07 per 1000 total births). There was a steady reduction in the prevalence of stillbirth from 38.07 per 1000 total births in 2012 to 13.22 per 1000 total births in 2016 (Table 2). Mothers with three or four children, mothers with secondary education, mothers who were traders, mothers who delivered in primary health care facilities and mothers 30 to 39 years old had the highest number of stillbirths (Table 1). 
Table 1: Proportion of mothers with stillbirth by their demographic characteristics $(\mathrm{N}=313)$

\begin{tabular}{|c|c|c|c|c|c|c|c|c|c|c|c|}
\hline & \multirow[t]{2}{*}{$\mathbf{n}$} & \multicolumn{2}{|c|}{2012} & \multicolumn{2}{|c|}{2013} & \multicolumn{2}{|c|}{2014} & \multicolumn{2}{|c|}{2015} & \multicolumn{2}{|c|}{2016} \\
\hline & & $\mathbf{f}$ & $\%$ & f & $\%$ & f & $\%$ & $\mathbf{f}$ & $\%$ & f & $\%$ \\
\hline \multicolumn{12}{|l|}{ Parity } \\
\hline 0 child delivered Alive & 97 & 23 & 23.7 & 16 & 16.5 & 13 & 13.4 & 21 & 21.6 & 24 & 24.7 \\
\hline 1-2 children & 66 & 14 & 21.2 & 14 & 21.2 & 13 & 19.6 & 17 & 25.7 & 8 & 12.1 \\
\hline 3-4 children & 102 & 25 & 24.5 & 23 & 22.5 & 17 & 16.6 & 22 & 21.6 & 15 & 14.7 \\
\hline 5 children and above & 48 & 12 & 25 & 10 & 20.8 & 8 & 16.7 & 3 & 6.3 & 15 & 31.3 \\
\hline \multicolumn{12}{|l|}{ Level of education } \\
\hline No formal education & 15 & 4 & 26.7 & 2 & 13.3 & 0 & 0 & 2 & 13.3 & 5 & 33.3 \\
\hline Primary education & 46 & 15 & 32.6 & 11 & 23.9 & 9 & 19.6 & 4 & 8.7 & 7 & 15.2 \\
\hline Secondary education & 238 & 52 & 21.8 & 46 & 19.3 & 42 & 17.6 & 52 & 21.8 & 48 & 20.2 \\
\hline Tertiary education & 14 & 3 & 21.4 & 4 & 28.6 & 0 & 0 & 5 & 35.7 & 2 & 14.3 \\
\hline \multicolumn{12}{|l|}{ Occupation } \\
\hline Unemployed/house wives & 90 & 19 & 21.1 & 21 & 22.3 & 11 & 12.2 & 24 & 26.7 & 17 & 18.9 \\
\hline Civil Servant & 24 & 4 & 16.7 & 5 & 20.8 & 5 & 20.8 & 5 & 20.8 & 6 & 25.0 \\
\hline Farmers & 21 & 5 & 23.8 & 5 & 23.8 & 6 & 28.6 & 2 & 9.5 & 2 & 9.5 \\
\hline Trader & 99 & 28 & 28.3 & 19 & 19.2 & 13 & 13.1 & 17 & 17.2 & 24 & 24.2 \\
\hline Skilled worker & 79 & 18 & 22.8 & 13 & 16.5 & 16 & 20.3 & 15 & 19.0 & 13 & 16.5 \\
\hline \multicolumn{12}{|l|}{ Health facility type } \\
\hline General Hospital & 79 & 17 & 21.5 & 15 & 18.10 & 11 & 13.9 & 19 & 24.0 & 17 & 21.5 \\
\hline Primary Health centre & 234 & 57 & 24.4 & 48 & 20.5 & 40 & 17.1 & 44 & 18.8 & 45 & 19.2 \\
\hline \multicolumn{12}{|l|}{ Mothers' age } \\
\hline$<18$ years & 27 & 7 & 25.9 & 5 & 18.5 & 3 & 11.1 & 7 & 25.9 & 6 & 22.2 \\
\hline $18-29$ years & 98 & 24 & 24.5 & 16 & 16.3 & 20 & 20.4 & 23 & 23.5 & 17 & 17.3 \\
\hline $30-39$ years & 114 & 27 & 23.7 & 24 & 21.1 & 14 & 12.3 & 25 & 21.9 & 22 & 19.3 \\
\hline 40 years and above & 74 & 16 & 21.6 & 18 & 24.3 & 14 & 18.9 & 8 & 10.8 & 17 & 23.0 \\
\hline
\end{tabular}

$\mathbf{n}=$ number in the group 
Table 2: Prevalence of stillbirth among mothers attending health facilities from 2012-2016

\begin{tabular}{lllll}
\hline & Year & $\begin{array}{l}\text { Total number of } \\
\text { birth }\end{array}$ & $\begin{array}{l}\text { Number of } \\
\text { still birth }\end{array}$ & $\begin{array}{l}\text { Stillbirth Per } \\
\mathbf{1 0 0 0}\end{array}$ \\
\hline 1. & 2012 & 1944 & 74 & 38.07 \\
2. & 2013 & 2364 & 63 & 26.65 \\
3. & 2014 & 2515 & 51 & 20.28 \\
4. & 2015 & 4331 & 63 & 14.55 \\
5. & 2016 & 4690 & 62 & 13.22 \\
& Total & 15844 & 313 & 19.76 \\
\hline
\end{tabular}

However, Table 3 showed that the prevalence rate of stillbirth was highest among mothers with one or two children, mothers with only secondary education, unemployed mothers, mothers who gave birth in general hospitals and mothers 40 years old and above. There were significant differences in the number of stillbirths when the mothers were classified based on their levels of education, occupation, type of health facility where delivery occurred and mothers' age. There was no significant difference in the number of stillbirths when the mothers were classified based on their parity (Table 3).

Table 3: Association between socio-demographic variables of mothers with stillbirths and stillbirth prevalence $(2012-2016)$

\begin{tabular}{|c|c|c|c|c|c|c|}
\hline $\begin{array}{l}\text { Socio-demographic } \\
\text { Variables }\end{array}$ & $\begin{array}{l}\text { Total } \\
\text { number } \\
\text { of births }\end{array}$ & $\begin{array}{l}\text { Number } \\
\text { of } \\
\text { stillbirths }\end{array}$ & $\begin{array}{l}\text { Prevalence } \\
\text { of stillbirth } \\
2012-2016\end{array}$ & df & $\chi^{2}$ & Sig $\mathbf{P}$ \\
\hline \multicolumn{7}{|l|}{ Parity } \\
\hline 0 child delivered Alive & 4753 & 97 & 20.41 & 3 & 0.0846 & .888 \\
\hline 1-2 children & 3169 & 66 & 20.83 & & & \\
\hline 3-4 children & 5545 & 102 & 18.39 & & & \\
\hline 5 children and above & 2377 & 48 & 20.19 & & & \\
\hline \multicolumn{7}{|l|}{ Level of education } \\
\hline No formal education & 951 & 15 & 15.77 & 3 & 179.615 & $0.000 *$ \\
\hline Primary education & 3169 & 46 & 14.52 & & & \\
\hline Secondary education & 6496 & 238 & 36.64 & & & \\
\hline Tertiary education & 5228 & 14 & 2.68 & & & \\
\hline \multicolumn{7}{|l|}{ Occupation } \\
\hline $\begin{array}{l}\text { Unemployed/house } \\
\text { wives }\end{array}$ & 1553 & 90 & 57.95 & 4 & 240.602 & $0.000^{*}$ \\
\hline Civil Servant & 1775 & 24 & 13.52 & & & \\
\hline Farmers & 1267 & 21 & 16.57 & & & \\
\hline Trader & 9665 & 99 & 10.24 & & & \\
\hline Skilled worker & 1584 & 79 & 49.87 & & & \\
\hline \multicolumn{7}{|l|}{ Health facility type } \\
\hline General Hospital & 2447 & 79 & 32.28 & 1 & 23.462 & $0.000 *$ \\
\hline Primary Health centre & 13397 & 234 & 17.47 & & & \\
\hline \multicolumn{7}{|l|}{ Mothers' age } \\
\hline$<18$ years & 1268 & 27 & 21.29 & 3 & 86.378 & $0.000 *$ \\
\hline $18-29$ years & 5545 & 98 & 17.67 & & & \\
\hline 30-39 years & 7605 & 114 & 14.99 & & & \\
\hline 40 years and above & 1426 & 74 & 51.89 & & & \\
\hline
\end{tabular}

*Significant at 0.05 level of significance 


\section{Discussion}

In the present study, the frequency of stillbirth was shown to be fairly high among childbearing mothers in Anambra state, Nigeria. Table 2 shows that the highest prevalence (38.07 per 1000 births) of stillbirth was in 2012 followed by a sharp drop in 2013 (26.69). The prevalence of stillbirth continued to drop but at a slower rate in 2014 through 2015. There was only a slight decrease in 2016 (13.22 per 1000) compared to the prevalence rate of 14.55 per 1000 in 2014. The steady decrease in stillbirth is not surprising. The decrease may be attributed to increased attention given to maternal health in the area of study within the period of study by the government and some nongovernmental organizations ${ }^{16,17}$ within the period of study. The finding is consistent with a previous research report that showed an annual Average Rate of Reduction (ARR) of only $2.0 \%{ }^{18}$ The decrease in the stillbirth occurrence could be attributed to the concerted effort by the government (Federal, State and LGA) to reduce infant mortality rate (IMR) in Nigeria as stipulated in Sustainable Devlopment Goal 3 (SDG) ${ }^{17}$ However, this result contradicts the findings of Lawn et al. ${ }^{2}$ that despite several interventions towards mitigating stillbirth in developing countries, stillbirth is still on the increase. This discrepancy may be due to aggregate estimate in Lawn et al. ${ }^{2}$ stillbirth prevalence in many developing countries including Nigeria. These pooled estimates might have increased the stillbirth prevalence in developing countries because stillbirth prevalence varies from one country to another and from one community to another.

Surprisingly, data in Table 3 showed that there was no significant difference in the proportion of stillbirth by mothers of varied parity. This contradicts literature assertions that stillbirth is associated with multiparity. ${ }^{19,20}$ Igwegbe, Nwosu, Ugboaja, et al ${ }^{21}$ however observed that unbooked primiparous and multiparous women experienced more stillbirths as a result of not booking or non-attendance at antenatal care during pregnancy. Therefore parity alone is not enough to predict stillbirth, other maternal factors such as attendance to antenatal clinic are capable of influencing pregnancy outcome.

Little wonder this study showed that maternal occupation is significantly associated with the prevalence of stillbirth among mothers (Table 3). Unemployed women and housewives had the highest prevalence of stillbirth within the study period. Employment is associated with financial empowerment and as such women who are gainfully engaged can afford to decide to use skilled attendant during antenatal and delivery period thus reducing their chances of having a stillbirth. Differences in the ability to access good quality obstetric services may be due to differences in maternal employment status as a pregnant woman with no occupation may not afford the cost of health services which may later result to home delivery. Azuh ${ }^{22}$ stated that good occupation will bring women on board the decision making realm including health care. The result agrees with the findings of Alhassan et al., ${ }^{23}$ which showed that unemployed childbearing mothers had higher stillbirth rate because of social inequality caused by education. Albeit, the result of this study showed that childbearing mothers who were civil servants had the highest proportion of stillbirth in 2016. In fact, the proportion of stillbirth among this category of women increased in 2013 reaching a peak in 2016 (Table 1). This result is very surprising. Civil servants are presumed to be more learned and financially stable enough to seek health care. The result however may be related to the progressive economic downfall in Nigeria since the present decade which has made many employers of labour unable to pay their workers within the period. This may have affected the ability of mothers who were civil servants to seek and procure needed care during pregnancy and childbirth. This result is in contrast with the finding of Mutihir and $\mathrm{Eka}^{20}$ namely that civil servants recorded low stillbirth proportion. The contrasting result in the current study may also be attributed to general occupational hazards which civil servants encounter during work. Such occupational hazards as standing for long hours, shift work, extremes of heat and cold, and working in an extremely hot environment are risky during pregnancy and have been reported to be associated with an adverse outcome such as stillbirth. ${ }^{24}$

It is also surprising that when the mothers were classified by their level of education, mothers with secondary education had the highest prevalence of stillbirth. It is however worthy of note that while education is supposed to reduce ignorance among women and increase their use of health care services including antenatal care, mothers who stopped at secondary education may be hindered by lack of employment since those with tertiary education 
do not find it easy to get good job particularly in Nigeria not to mention those with only secondary education. Hence this half education is capable of barring them from learning a trade and not enabling them to acquire skills that will help them to become self-employed. This is illustrated in this study by the fact that mothers with tertiary education had the lowest prevalence rate of 2.68 per 1000 births during the period of study while those with only secondary education had the highest prevalence rate of 36.64 per 1000 births. The fact that those mothers with no formal education and those with only primary education had an even lower prevalence of stillbirth than mothers with only secondary education suggest that the problem is not with education alone but that there are other factors which could include economic empowerment. Women with no formal education or just primary education know that they do not have a chance at a white-collar job and so they start early to learn a skill or trade that will make them self employed hence they become economically more empowered than their counterparts with secondary education who keep hoping for white-collar job which they rarely get. The finding contradicts the findings of Lofwander ${ }^{24}$ which showed that stillbirths were three times higher in uneducated mothers than in high educated mothers. Equally, Ugwa and Ash$\mathrm{imi}^{25}$ Mutihir and $\mathrm{Eka}^{20}$ have shown that stillbirth was higher in women with no formal education with the rate of stillbirth decreasing with increasing educational status. The finding of this study may however, be attributed to unemployment, late booking and lack of prenatal care during pregnancy. Many women in the study area are gainfully self-employed as farmers, skilled workers and traders even with no formal education or minimal education. Such gainful employments appear to have given them the financial edge over the mothers with only secondary education who are not gainfully employed.

Data in Table 3 shows that the prevalence of stillbirth is significantly associated with the kind of health facility the mother was delivered in. General hospitals had a higher prevalence rate of 32.28 per 1000 birth while primary healthcare centres had a prevalence rate of 17.47 per 1000 births. This is not surprising since general hospitals are secondary health facilities and as such, they receive complicated cases referred from primary healthcare centres. It has been shown in literature ${ }^{26}$ that mothers with complications are at higher risk of stillbirth than mothers without complications. Therefore since the general hospitals care for complicated cases while the primary healthcare centres attend to normal pregnancy cases, the general hospitals are bound to record more negative outcomes of stillbirth than primary health care facilities.

Table 3 shows that prevalence of stillbirth was highest among mothers 40 -year-old and above (51.89 per 1000 births), followed by those 18 years and younger (21.29 per 1000 births) within the study period. This result is not surprising. This is because pregnancies occurring at extremes of women reproductive ages are high-risk pregnancies for both mother and newborn. ${ }^{18}$ Childbearing mothers belonging to the extremes of the age have a higher risk of experiencing pregnancy-induced hypertension or gestational diabetes and these place them at greater risk of stillbirth. ${ }^{18}$

\section{Limitations of the study}

A major limitation of the present study is that some health facilities in the process of renovation could not recover their delivery registers; hence, such stillbirth records were not included. Again, associations between the demographic characteristics of mothers and stillbirth were based only on univariate analysis. As the study was a retrospective analysis of data obtained from delivery registers, we were unable to examine such probable confounding factors as occupational hazards of the pregnant mothers and lack of prenatal care which could be associated with an adverse outcome such as stillbirth. ${ }^{24}$

\section{Conclusions and recommendation}

The prevalence of stillbirth is fairly high in the study area. Mothers' level of education, age, occupation and health facility where the mother was delivered of her baby significantly influenced the prevalence of stillbirth among the childbearing mothers. This study therefore, underscores the need for community-based public health interventions to drastically reduce the occurrence of stillbirths among rural women with limited resources. We therefore, recommend that women empowerment should be a priority at both family and community level to enable women to seek and obtain necessary care during pregnancy and delivery. General health facilities should be well equipped with human and material resources to enable them to take care of complicated cases with minimal negative outcome such as stillbirths. 


\section{Conflict of interest}

None declared.

\section{References}

1. Ouyang F, Zhang J, Betrán AP, Yang Z, Souza JP, Merialdi $M$. Recurrence of adverse perinatal outcomes in developing countries. Bulletin of the World Health Organization 2013; 91: 357-367.

2. Lawn JE, Blencowe H, Waiswa P, Amouzou A, Mathers C, Hogan D et al. Stillbirths: rates, risk factors, and acceleration towards 2030. Lancet Series 2016; 387: 100 $-118$.

3. Tukur D and Alhaji AA. Stillbirth in Nigeria: Rates and Risk factors based on 2013 Nigeria DHS. Open Access Library Journal 2016; 3: 1-12. doi: 10.4236/oalib.1102

4. Jannah I. What is the significance of childbirth in Igbo land? http://obindigbo.com.ng/2015/03/what-is-thesignificance-of-childbirth-in-igboland/

5. Omo Aghoja LO, Onohwakpor EA, Adeyinka AT, Omene JA. Incidence and determinants of stillbirth amongst parturients in two hospitals in Southern Nigeria. Journal of Basic and Clinical Reproductive Sciences 2014; 3(1):15-21.

6. WHO. The neglected tragedy of stillbirths, 2016. https://www.who.int/reproductivehealth/topics/maternal_perinatal/stillbirth/Lancet-series/en/

7. Agbata AT, Eze JN, Ukaegbe CI, Odio BN. A 4-year retrospective review of stillbirths at the Federal Teaching Hospital, Abakaliki, Southeast Nigeria. African Journal of Medicine and Medical Sciences 2017; 16:19-24

8. Human M, Green S, Groenewald C, Goldstein RD, Kinney HC, Odendaal HJ. Psychosocial implications of stillbirth for the mother and her family: A crisis-support approach. Social Work 2014; 50(4):563-80.

9. Frøen JF, Cacciatore J, McClure EM, Kuti O, Jokhio AH, Islam M, et al. Lancet's Stillbirths Series Steering Committee. Stillbirths: why they matter. The Lancet 2011 Apr 16; 377(9774):1353-66.

10. Radhakrishna S. Culture of blame in the National Health Service; consequences and solutions. British Journal of Anaesthesia 2015; 115 (5): 653-655.

11. Cheptum JJ, Muiruri N, Mutua E, Gitonga M, Juma M. Correlates of Stillbirths at Nyeri Provincial General Hospital, Kenya, 2009-2013: A Retrospective Study. International Journal of MCH and AIDS 2016; 5(1): 24-31.

12. Ugboma HAA and Onyearugha CN. Still Births in a Tertiary Hospital, Niger Delta area of Nigeria; Less Than a Decade to the Millennium Developmental Goals. In- ternational Journal of tropical disease and Health 2012; 2(1): 16-23.

13. Okeudo C, Ezem BU and Ojiyi EE. Stillbirth Rate in a Teaching Hospital in Southeastern Nigeria: A Silent Tragedy. Annals of Medical and Health Sciences Research 2012; 2(2): 176 -179. doi.10.4103/2141-9248.

14. Unachukwu GC, Ojiakor N, Okafor G, editors. Nigerian peoples and culture. John Jacob's Classic Publishers; 2003.

15. Daniel $\mathrm{T}$ and Kostic B. RStats chi-square calculator 2017, http://www.missouristate.edu/rstats/Tables-and-Calculators.htm (accessed 11 May 2018).

16. Edu BC, Agan TU, Monjok E, Makowiecka K. Effect of Free Maternal Health Care Program on Health-seeking Behaviour of Women during Pregnancy, Intra-partum and Postpartum Periods in Cross River State of Nigeria: A Mixed Method Study. Open Access Macedonian Journal of Medical Sciences 2017; 5(3):370-382. doi:10.3889/ oamjms.2017.075.

17. Anambra State Ministry of Health and FHI 360. Anambra State-wide Rapid Health Facility Assessment. Nigeria: Anambra State Ministry of Health and FHI 360, 2013.

18. WHO, UNICEF, UNFPA, World Bank Group, UN Population Division (2016) Trends in Maternal Mortality: 1990 to 2015.

h t t p : / / a p p s.w ho.int / i r is / bits tre am/10665/194254/1/9789241565141_eng.pdf?ua=1

19. Reddy U. Work up of stillbirth: a review of the evidence. American Journal of Obstetrics and Gyneacology 2007; 196 (5): 433-44.

20. Mutihir JI, Eka PO. Stillbirths at the Jos University Teaching Hospital: Incidence, Risk, and Etiological Factors. Nigerian Journal of Clinical Practice 2011; 14: 14-18. 21. Igwegbe AO, Nwosu BO, Ugboaja JO, Monago NE. Stillbirth in a Nigerian Tertiary Hospital. Nigerian Medical Journal 2008; 49: 74-78.

22. Azuh, D. Socio-demographic factors influencing health program usage by pregnant mothers in Nigeria: Implications for policy action. A paper presented at the sixth African union conference, Burkina Faso 2011, http://uaps2011.princeton.edu/papers/110940 (accessed 7 January 2018)

23. Alhassan A, Ayikai LA, Alidu, H, Yakong VN. Stillbirth and associated factors in a Peri-urban District in Ghana. Journal of Medical and Biomedical Sciences 2016; 5 (1): 23-31.

24. Lofwander, M. Stillbirths and associations with ma- 
ternal education. A registry study from a regional hospital in north eastern Tanzania. Epidemiology and Community Health 2012; 66 (7): 240-246.

25. Ugwa EA, Ashimi A. An assessment of stillbirths in a tertiary hospital in northern Nigeria. Journal of Maternal-Fetal and Neonatal Medicine 2015; 28 (13): 1585-1588.
26. Goldenberg RL, McClure EM, Bann CM. The relationship of intrapartum and antepartum stillbirths rates to measures of obstetric care in developed and developing countries. Acta obstetricia et gynecologica Scandinavica 2007; 86: 1303-1309. 